Article

\title{
The Consequences of Human Behavior
}

\section{Derek Hodgson}

Palaeocentre, University of York, Heslington, York YO10 5DD, UK;

E-Mail: dehogson@googlemail.com

Received: 26 October 2012; in revised form: 26 November 2012 / Accepted: 27 November 2012 / Published: 10 December 2012

\begin{abstract}
Human behavior is founded on a complex interaction of influences that derive from sources both extraneous and intrinsic to the brain. It is the ways these various influences worked together in the past to fashion modern human cognition that can help elucidate the probable course of future human endeavor. A particular concern of this chapter is the way cognition has been shaped and continues to depend on prevailing environmental and ecological conditions. Whether the human predicament can be regarded simply as another response to such conditions similar to that of other organisms or something special will also be addressed. More specifically, it will be shown that, although the highly artificial niche in which most humans now live has had profound effects on ways of thinking, constraints deriving from a shared evolutionary heritage continue to have substantial effects on behavior. The way these exigencies interact will be explored in order to understand the implications for the future wellbeing of humanity.
\end{abstract}

Keywords: human evolution; population; mind; environment; primates; tools; information processing; brain

\section{Introduction}

It was quite recently thought that perhaps humans or Homo sapiens sapiens (hereafter Hss), to give this species its correct etymological name, was simply a more sophisticated version of a chimpanzee. Although this idea stimulated much popular acclaim, it was primarily based on the notion that humans evolved some six million years ago from a chimpanzee-like species with the latter remaining unchanged when, in fact, both humans and chimpanzees have undergone their own evolutionary trajectories since diverging from a yet unknown common ancestor. In effect, the chimpanzees of today may be completely different from their ancestors in the same way that humans differ from hominin 
ancestors both physically and mentally. Given very few fossils exist that can specify the heritage of any of the great apes, it is more than likely they underwent considerable evolutionary change different to that of Hss [1]. This, it should be emphasized, does not presuppose a discontinuity between Hss and other primates, rather the behavioral profile of humans needs to be seen in relative terms as distinct from that shared by other primates.

Although it is obvious humans are, in fact, primates, the question arises as to what led to the differences that separate Hss from all nonhuman primates. In other words, are we special, and, if so, how did this come about? Addressing these questions may help formulate a better understanding of the issues regarding the human condition and the consequences for what has been termed the Anthropocene [2]; where it is acknowledged humans have altered the world extensively through niche construction to the extent that this now impacts on the environment and ecology in significant ways. These issues have important implications not just for the future of humans as a species but also the other organisms with whom we share the planet. In order to explore these questions, I begin with a consideration of brain evolution, after which I show how this relates to population dynamics, cumulative culture, the construction of social groups and extended communities. The emphasis throughout will be to demonstrate that the behavior of $H s s$ was shaped by the prevailing environmental context whether natural or artificial.

\section{The Basis of Human Behavior}

\subsection{Evolution of the Human Brain}

The common ancestor of chimpanzees and Hss is now thought to be a completely different entity anatomically and cognitively to any modern-day primate. In the case of Homo, this has been confirmed by Ardipithicus ramidus, a four and half million year old hominin whose anatomy already exhibited some of the anatomical traits that typify humans [3] (some yet older species such as Sahelanthropus and Orrorin tugenensis provide further corrobotation) including feet adapted more to bipedalism and reduced sexual dimorphism. In fact, a lack of aggression among males and between groups seems already in evidence in Ardipithicus as manifest in the similarity in canine size between males and females compared to the pronounced differences found in chimpanzees [3]. Along with Ardipithicus, Orrorin and Sahelanthropus, the australopithecines are thought to be, if not one of our earliest ancestors, then something quite similar. A fact often mentioned is that the brain of this species is about the same size as modern-day chimpanzees. However, considering the reservations already alluded to, it seems imprudent to draw firm conclusions regarding similarities in behavior between australopithecines and chimpanzees. This is especially so, as what made Australopithecus a separate species was the very fact they inhabited a different ecological niche and were probably responsible for making some Oldowan tools [4], which, although rudimentary, are beyond the capability of chimpanzees in their natural environment [5] (it has, however, recently been shown that bonobos can produce simple core and flake tools but this was achieved in an artificial environment with human-savvy apes [6]). The ability to extend the body by employing implements led to a "techno-organic" proclivity, where teeth were supplemented by tools leading to a reduction in both teeth and jaw size [5]. In essence, tools became external incisors that could be utilized in various ways for extracting food resources and 
improving hunting and foraging outcomes. Moreover, it may not have been brain size alone that led to improved cognitive abilities but neural reorganization, which is discernible in the brain of Australopithecus three and a half million years ago [7] (though this continues to be contested) suggesting that the neural systems required for integrated thinking were already in the making. Changes in brain organization in early hominins seems to have led to an adaptive radiation where a host of similar species existed alongside Homo erectus, a fact recently confirmed by recent discoveries of two new hominins from Kenya [8]. Given that there were a number of hominin species vying for the same niche, why, then, are we the only species of this genre to have survived in contrast to other large primates that are anatomically similar? - a question that will be addressed in due course. It is probable that the evolutionary driving force leading to brain enlargement and reorganization was mediated by the advantages to be gained from the social interaction required in belonging to increasingly larger groups $[9,10]$. The means by which this transpired provides an interesting insight into how human behavior and socio-cultural traits evolved.

\subsection{The Emergence of "Mind"}

Although the enlargement and reconfiguration of the brain began at an early date, perhaps an equally important factor concerns the immediate phenomenological awareness experienced by the mind. Such experience is obviously directly related to consciousness but, as demonstrated by modern neuroscience, consciousness is a sophisticated compelling illusion [11,12]—which may have partly evolved from the needs required for a highly social brain. Although it is thought nonhuman primates possess a rudimentary conscious sense, this is restricted to the here and now due to a limited memory tied to immediate circumstances [13]. A slightly larger more interconnected brain would have allowed early hominins to begin escaping the tyranny of the present in that the neural networks were able to hold information in reserve for further consideration [14]. Integration of this kind is essential for the ability to make tools some 2.4 million years ago as it involves interlinking a number of cognitive modules such as visuo-spatial, perceptual and imitative faculties. This ability, although realized in the mind, therefore originated from making simple tools and the increased social interaction accorded, both which required extra information-processing capacities in the brain. One advantage of this was the ability to plan on a number of levels, e.g., coordination of resources over time, acting out scenarios for better performance in actual situations, predicting events, etc.

A better understanding of the mind has been furthered through evolutionary psychology [15] where human thinking is deemed to stem from, and even now continues to rely upon, evolutionary criteria that promoted the survival of hominins over the long term through the environment of evolutionary adaptiveness. There are several reasons why evolutionary instantiated domains persist in the mind, including the poverty of stimulus and a combinatorial explosion whereby it is impossible to correlate and organize all new environmental information ontogenetically [16]. Put another way, evolution has provided cognitive systems predisposed to detect and assimilate certain environmental and social cues crucial to human survival, which means each individual does not need to learn anew the intractable complexities appertaining (which would be impossible given the lifespan of humans). Such constraints are thought to emanate from the modular structure of the brain involving specialized areas for processing specific kinds of information such as faces (for decoding facial expression and mood), 
animals and organic forms (for the detection of potential predators and food), tools (for making and manipulating objects) [16]. In addition, there are more diffuse cognitive domains relating to folk psychology (providing guesses as to how others think), cheater detection, foraging mechanisms, alliance-tracking, agent detection, etc. These domains provide a foundation on which present-day human cognition is based as such long-term evolutionary instantiated faculties cannot be countermanded by more recent short-term cultural events. For example, an immediate fear of snakes and spiders continues to exist although no such fear response exists for cars that kill and maim far more people in modern technological societies. Moreover, phobias for snakes and spiders, as well as animals in general, are far more frequent and are extremely difficult to counteract in modern populations compared to phobias concerning everyday objects [17]. It is pertinent that many phobias and anxiety syndromes are also associated with fear of social contact that lead to social exclusion and isolation. Interestingly, when individuals feel under threat or are emotionally aroused (e.g., when panic ensues), these domains become more pronounced and dictate behavioral outcomes. Conversely, when conditions are favorable with resources in abundance, individuals tend to over indulge even when this is deleterious to health. For example, as sweet fruits and salt were often in short supply, now that sugared foods and salt are cheap and readily available these items tend to be over-consumed leading to obesity and associated illnesses e.g., increased risk of diabetes, heart problems, high blood pressure. Preferences of this kind are particularly significant because they stem from the way the mind has been structured by the evolutionary past of Homo. Such enduring biases depend on the predilection of the brain for particular items or set of behaviors that become abnormal in situations of abundance and are often manifested culturally by an obsession for certain objects or activities.

The important contribution of evolutionary psychology to understanding the human mind, therefore, is that, contrary to the recent commonly held view that the mind is infinitely pliable, it appears thinking continues to be channeled and constrained by our evolutionary past, which has consequences for how humans relate to the world. From this perspective, the dichotomy of innate versus learned or biological versus cultural dissolves as all evolved mechanisms require environmental input to be realized [18]. The recent "new thinking", which challenges evolutionary psychology by positing the primacy of general learning mechanisms mediated by immediate environmental input [19], can be assimilated with the above analysis in that one important aspect of human behavior is emphasized - namely the obvious flexibility to certain situations. Seen from this standpoint, Hss is endowed with a propensity to learn that was shaped by past evolutionary events. Human behavior therefore has to be regarded as a complex suite of traits, some that are channeled by evolutionary instantiated cognitive domains whereas others are more flexible and responsive to immediate circumstances, including the presiding cultural context [18]. This reflects the gene-culture co-evolutionary framework that is increasingly referred to by scholars from various disciplines assessing how human behavior relates to evolution [20].

\subsection{The Slow Development of the Human Mind}

Although humans share a large part of their genes with chimpanzees, this similarity needs to be viewed in the context of that which really separates humans from other primates that takes place during development of the phenotype in relation to what is termed "evo-devo" [21]. This is 
underscored by the fact genes are not static blueprints that determine the course of development but are dynamic agents that respond to environmental input during development itself. Thus, genes are more like sensitive switches that can be turned on and off during development in response to environmental cues. Nevertheless, although genes respond dynamically to environmental input, the leeway extended is dictated by previous enduring evolutionary constants appertaining to Homo as a species that is encoded in the genotype. Thus, the behavior of a species is determined by its evolutionary past that can be tempered by environmental circumstances within the limits specified by the overarching genetic code. One of the main environmental influences affecting human development is socio-cultural input, which needs to be factored in when considering how cognitive development proceeds. The much longer period of development in humans compared to other primates, as expressed in neoteny and pedomorphism (retention of juvenile features), suggests socio-cultural factors became crucial to human behavior [22], probably as early as 500,000 years ago if not before. Indeed, cumulative culture became particularly important to humans on a number of levels, especially when the associated environmental niche became progressively artificial. It seems that the escalating dependence on cultural evolution in Homo, which was sifted through existing adaptive biases, evolved as a way of counteracting both immediate experience and rudimentary intuitive responses [23].

\section{Group Selection}

The question arises as to how culture became so vital to human survival and identity. Although Darwinian evolution is based on the individual rather than the group, there has been a growing tendency to regard humans as an exception in that the group has become crucial to hominin evolution. Indeed, a growing consensus posits that what differentiates humans from nonhuman primates is group dynamics thanks to a co-evolutionary epigenetic process that encompasses socio-cultural factors [20,24]. Cultural group selection is therefore increasingly referred to as a way of explaining archeological and anthropological data during the late Pleistocene [25,26]. As Hss is the only primate able to function at this level, it has been surmised this is because a significant adaptive valley needed to be crossed [26], which suggests Homo evolved along a specific evolutionary trajectory that, once begun, could not easily be retraced. This is especially the case with a large brain that comes with a considerable number of problems such as the amount of energy consumed, difficulties at birth, the alignment of such a heavy organ on top of an erect body, and the increased vulnerability associated with an extended childhood.

An enlarged, more complex brain is associated with an extended social group size [27]. Thus, compared to chimpanzees, humans form extensive social groups composed of relatives and non-relatives in both small and larger communities. Although the core group can range up to 150 individuals, with the arrival of institutional organizations group numbers expanded to thousands with the ability to form cross-group alliances, trading ties, and intermarriages. Conversely, in chimpanzees, the appearance of chimpanzees from neighboring groups leads to aggression rather than cooperation [28], though this seems not to be the case with bonobos. Humans occupy a midway position between these two primate groups (recently confirmed by neuroimaging of chimp and bonobo brains [29]) as, besides cooperative behavior, Hss often indulge in bouts of aggression and violence towards out-groups. Bonobos, however, have been found to be more cooperative than chimpanzees in 
tasks requiring more than one individual to retrieve a food item in that they not only help one another but share the food obtained [30]. This confirms the "emotional-reactivity hypothesis" where the control of temperament is crucial to prosocial behavior, a capacity in which humans excel. In this respect, research has found that, although chimpanzees and humans share prolonged development of prefrontal white matter after birth, only humans exhibit a dramatic increase in prefrontal white matter during infancy, which is associated with complex social abilities [31]. Thus, human cooperation involves both kin and significant non-kin, which applies to the smallest hunter gatherer groups [32,33]. Such extended cooperation as a means of expelling free riders and cheaters from a community through collective decision making which, through a co-evolutionary mechanism, eventually led to prosocial behavior that was reinforced by cultural imperatives.

Hence, one of the main evolutionary driving forces that gave rise to the Homo line concerns social communication. Dunbar [10,34-36], for example, has shown that early Homo probably replaced time-consuming grooming for maintaining alliances, common in non-human primates, with a more efficient communication system that led to speech thus allowing a greater number of individuals to participate in an alliance network. Dunbar, convincingly, shows that the number of individuals in such a network correlates with brain size; a view that is not incompatible with the reorganization of important neural structures. However, enhanced social interaction did not evolve in isolation as it would have been connected to a raft of important co-occurring events involving the use of tools, improved communicative abilities for hunting and foraging, and a degree of specialization in functions promoting extended childrearing [9]. For example, it has been found that when chimpanzees are taught to make and use tools, this increases socialization [37]. From this standpoint, a number of factors acted together in that, in order for brain size to increase, a diet rich in meat and associated animal products was required [38], which could only proceed with the invention of better tools, the making and use of which (especially in hunting large game) necessitated more sophisticated communicative modes. These factors were therefore bound together within the context of a social system where group numbers could increase. It is thought male-female bonding (as in romantic love) arose in this context by allowing males to be absent from the home base while hunting that served as a means of creating permanent ties between the sexes necessary to provide sufficient level of protection and care for children over an extended period [9]. These factors coalesced to establish the artificial niche that typifies human material culture [39] — whether this was realized in practical technologies or artifacts with no obvious practical efficacy (e.g. art-like objects). In sum, these various factors allowed a social system to emerge based on trust that extended beyond immediate kin to encompass significant others in a community. Aggression, however, continued to be part of the psychological profile of hominins, yet this was counterbalanced, if not transcended, by an increasing tendency to engage in cooperative behavior.

\section{Small and Large Scale Societies}

Compared to 50-60 in nonhuman primates, extended social networks based on trust allowed natural group size to expand significantly in hominins which, according to brain size correlation, approached 120-130 individuals by about 500,000 years ago [10,40]. When this size is reached, new founder populations tend to split from the main group to form new communities. In Hss, the maximum 
functional group size is believed to be approximately 150. This is because, in groups limited to no more than 150, it is possible for individuals to keep personal track of other group members that is difficult when this number is exceeded, which is probably the main reason new founder groups emerge when this number is surpassed. One way this number can be circumvented to permit much larger population levels within a specified group is through culture. However, before discussing the merits of culture, we need to determine the factors that gave rise to its emergence.

Although chimpanzees evince some basic cultural traits as manifest in different tool types and certain behaviors, these are not concerted group-oriented practices accumulated over time that arise from intentional/informed instruction. In chimps, emulation and stimulus enhancement, with some minimal evidence for true imitation, seem to be the primary way information is acquired [41]. In humans, imitation is not only over-learned and proceeds with great fidelity at an early age (beginning at about two years of age) but is also more sophisticated. This ability is thought to derive from an enhanced mirror system supplemented by a theory of mind that is able to deal with 4-5 levels of intentionality [10] premised on, (a) conscious experience projected beyond the present, (b) a capacity to understand the minds of others in order to evaluate emotions that facilitates social behavior, (c) an ability to employ these faculties flexibly over an extended timeframe thanks to a formidable episodic memory that is able to keep track of a considerable number of individuals based on their previous behavior [42]. These traits permitted hominins to engage in extended social interactions and facilitated the preservation of knowledge and transmission of ideas inter- and intra-generationally. As a result of these capacities, modern humans benefitted from increased levels of social interaction beyond that attainable by closely related hominins, including Neanderthals. In this regard, the material culture of anatomically modern humans may, in many respects, appear equivalent to Neanderthals [43], but when population levels rose in either species, it was Hss that profited the most $[44,45]$. This is due to the fact the upper population limit at which anatomically modern humans function as a group appears to be larger than that of Neanderthals [36,40]. The reasons for this may reside in the fact that the parietal lobes, where diverse information is coordinated (especially in relation to mirror neurons and theory of mind), is larger in modern humans compared to Neanderthals [46-48].

One of the effects of human brain enlargement and reorganization in response to the need for greater social interaction, more efficient predatory/foraging abilities, and tool making expertise, is the ability to "think outside the box." In other words, the evolutionary parameters that led to brain growth/reorganization allowed one to reflect on matters not always limited to evolutionary instantiated domains. This capacity can be regarded as a non-functional co-opted corollary of a larger reorganized brain (extra cognitive baggage, as it were) that benefitted survival but at the same time facilitated maladaptive behavior as realized in culture [49]. Thus, although culture allowed Hss to adapt to the changing environmental conditions of the late Pleistocene through the sharing of skills, an inevitable consequence of this was that individuals became susceptible to the beliefs of others, which allowed maladaptive ideas to take root and spread in the sense that individuals became prone to deception. In other words, one of the inevitable costs that came with a complex brain equipped with a prodigious theory of mind, was a liability to be deceived by ideas that could easily spread through a community, especially in such a highly social species as Hss. It was this extra cognitive baggage that fostered a belief in the supernatural and associative thinking (linking entities not in reality linked as for example in animism) as manifest in ritual activities (repeated actions and ceremonies regarded as capable of 
influencing various entities) and belief systems regarding ancestor worship, gods, spirits, and suchlike (that was usually manifested in "art-like" activities). This meta-cognitive faculty seems to have had an adverse effect on human evolution in that supernatural agents were regarded as real and, because this was based on an "irrational" interpretation of the world (which was nevertheless still a way of trying to understand it and important to those concerned) led to behavior not always in the best interests of early humans. For example, resources were often directed towards activities such as creating artifacts to appease gods, such as the large figurines of Easter Island, which could have been better spent alleviating prevailing environmental problems. In the case of Easter Island, such behavior was the exact opposite to what was required to avoid disaster as the creation of the large stone figurines necessitated cutting down the last remaining trees of the island. In fact, such behavior may have delayed human "progress" even in the face of social cooperation and practical skills (the transmission of these skills, however, will have occurred more frequently within rather than between groups). It should be added, here, that such thinking is not confined to the past as, even in modern industrialized societies based on post-enlightenment objectivity, this mode of relating to the world often dominates [50,51]. Moreover, post-enlightenment thinking itself is not without limitations in relation to confronting social issues and environmental concerns.

Human mental capacities, thus, seem to have derived from living in groups larger than that typical of both nonhuman primates and closely related hominins, and which continues to be tied to belonging to such extended groups. As stipulated, the coherence of a community can be maintained through the ability to detect and deal with free riders by way of a cheater detection mechanism, which may be one of the main reasons gossip exists [44]. However, as groups became larger and exceeded the natural limit of 150, cultural markers became critical, especially with the advent of sedentary lifeways. An important aspect of this relates to the in-group and out-group, whereby the in-group protects a certain territory that can be beneficially exploited with boundaries signified by particular activities, behaviors, and markers. This inevitably leads to confrontation with groups occupying adjacent territories which, in chimpanzees, often gives rise to extremely violent behavior toward the out-group by marauding male gangs [28]. It is clear this behavior has always been part of the human repertoire yet there are important differences that need to be addressed. Although humans seem to occupy a position halfway between chimps and bonobos in the aggression-cooperation continuum, this must have been biased towards cooperation otherwise humans would not formed large cooperative societies that began to occur during the Neolithic, if not before. This confirms that Hss is endowed with cognitive capacities associated with an evolutionary past spanning six million years very different to those that characterize either chimps or bonobos [36].

\section{Self-Domestication and Group Markers}

One of the main ways humans differ from nonhuman primates concerns the artificial niche created by the former. Although nonhuman primates are capable of making a range of tools for various purposes, they do not intentionally demonstrate this to others in a structured way [52]. The ability to learn from others has allowed humans to construct an artificial niche that pervades all areas of life allowing them to inhabit an environment somewhat disengaged from the natural world. One of the consequences is that the evolutionary dictates that gave rise to humans has, to some extent, been 
neutralized in that it is the artificial niche which now influences the way evolution affects Hss [53]. This allowed self-domestication to occur whereby, in the same way that the brains of dogs have reduced in size due to domestication, so the human brain has reduced in size, which has been accompanied by a gracilization of physical characteristics as a consequence [54]. A reduced brain size, however, does not necessarily lead to an inability to deal with complexity as this is thought also to depend on brain organization involving dendrite arbor, white matter conduction speed, and proliferation of the arcuate fasciculus $[22,55,56]$. Although a large complex brain has generally been advantageous, it has engendered maladaptive traits in that many psychiatric problems are associated with such a hyper-complex neural system [57,58]. Since diverging from the last common ancestor of chimpanzees and bonobos, the hominin brain has increasingly exploited a modular localized neural system embracing a modicum of integration with that of an increasing generalized ability $[59,60]$ as a result of transcriptional networks undergoing evolutionary remodeling - especially in the frontal lobe [56]. Appositely, it is the larger modules of the human brain, namely the hemispheric asymmetries, which are thought to be particularly vulnerable to malfunction in humans [61], particularly as a prolonged juvenile period is required for such asymmetries to develop [58].

One way extended communities were able to transcend the natural 150 population limit was by accentuating any slight differences marking out a community. This was achieved by exploiting aspects of the body through, for example, the use of different colored ochre, which may have allowed group allegiance to be identified at perhaps an early date [62]. When groups became sedentary, these markers began to take on great significance as a means of delineating territory that not only allowed the 150 population limit to be transcended, but also meant that such territory, while providing increased food resources, also needed to be defended against competing groups. Culturally defined markers therefore became an important means of keeping track of the community to which a person belonged, especially in settled agricultural economies where population levels had expanded. Because 150 people represents the upper limit that can be kept track of by each individual in a group by way of a trust network (through managing personal reputation), a means of tracking allegiances in groups exceeding this number became essential. So, although the use of these markers may have occurred relatively early_perhaps as early as 500,000 years ago - they began to be invested with greater significance and were exploited with greater effect with the arrival of settled communities.

Although cultural markers became progressively more important to settled communities, ritual seems to have already been practiced by anatomically modern humans 200,000 years ago, if not before [63-65]. For example, the 160,000 year old Homo sapiens idalto skulls seem to have been defleshed and were possibly carried in a sac [66] and evidence of areas set aside for ritual have been found at the 300,000 year old site of Bilzingsleben [67]. In addition, Homo heidelbergensis is thought to have indulged in incipient rituals where 32 bodies appear to have been deliberately cast into a pit [68] (also see Pettitt [68] for a review of evidence of ritual activity before the Upper Palaeolithic). Ritual appears to have been a means by which the world could be "explained" as a result of the aforementioned extra cognitive capacity linked to conscious awareness. In this sense, ritual can be regarded as an inevitable outcome of the mental apparatus of consciousness; the latter which allowed the world to be interpreted and gave the impression the underlying forces deemed responsible could be controlled or appeased. On the one hand, cumulative culture provided positive outcomes in allowing a community to respond more quickly than genetically based determinants or straightforward personal 
experience $[20,23,69,70]$ whereas, on the other hand, it led to maladaptive behavior that was not always beneficial to the survival of the individual or group, usually as a result of associative thinking. Yet, it seems that prosocial behavior ultimately prevailed over maladaptive tendencies.

Thus, in settled communities where the 150 population boundary had been crossed, the tracking of each individual to gauge social allegiance became cognitively problematic that led to costly displays developing, as embodied in rituals, which helped identify those lacking commitment to the group and promoted the delineation of group boundaries. In this sense, gods and other supernatural agents served as a policing system that were culturally selected to create conformity and cohesion that inevitably led to greater competition with out-groups [71]. Cultural group selection is, therefore, thought to have given rise to religious beliefs and ritual through manipulating human psychology as a way of increasing group solidarity and commitment [23] but which was deleterious to those restricted to the lower social ranks who became liable to exploitation - in contrast to those in the upper strata of society who benefited the most from this situation.

Other-worldly agents were, therefore, an evolutionary by-product in the sense that they did not arise through natural selection but were an unavoidable consequence of both theory of mind and conscious awareness, which was then co-opted by way of culture for controlling behavior in both extended and unrelated groups [71]. "Art", as such, did not exist as a separate discipline in this context, rather it was integral to the ritual process and may have been culturally selected due to the fact it is easily accommodated by human cognition [72]. One consequence of an increased dependence on group interaction and norms is that the human mind is formulated to expect the existence of a world that embraces such norms, which is believed to have originally facilitated the formulation of established institutions [73] i.e., institutionalized religions that developed from supernatural belief systems through intergroup rivalry.

It may have been the case, however, that before the rise of formal religious organizations, which were able to direct behavior according to specific rules, associative thinking was pursued in a rather ad hoc way. In situations of threat, due for example to environmental problems such as a draught or aggression from an out-group, emotionally derived factors tend to direct behavior in that supernatural entities are appealed to with greater frequency. This tendency seems to be the default mode in such circumstances and is easily roused in both modern and premodern groups. Indeed, the long period before the settled agricultural communities of the Neolithic from 500,000 to around 10,000 years ago, was characterized by relatively slow pace of practical innovation that may have been due to an over concern with activities and thought processes linked to associative thinking, as indicated by the Berekhat Ram and Tan Tan figurines dating to over 400,000 years ago [68]. Around 50,000 to 40,000 years, and possible as early as 100,000 years ago, a more rapid turnover of tool types [20] seems to have been accompanied by a rise in population levels [74-77] — of which the implications will be discussed presently. In short, the moralizing high gods of late complex societies seem to have been absent from early small scale hunter-gatherer societies [78], although ritual activity will have been practiced in the latter to ensure conformity.

In summary, the human psyche consists of a complex interaction of various factors, including some specifically linked to our evolutionary past that constrain behavior, some that give rise to associative thinking, whereas others are based on social interaction and the practical everyday problems of 
survival. However, it needs to be emphasized that it was only relatively late in human endeavor that practical utilitarian solutions for dealing with the world began to come to the fore.

\section{Tracing the Rise of "Civilization"}

\subsection{Agricultural Communities}

Evidence from archaeology suggests that human societies began to increase markedly in size from about 14,000 to 12,000 years ago when the first pre-agricultural villages appeared [79] (though, of course, population levels also increased and waned at much earlier periods in association with communal activities but this occurred within a completely different socio-cultural context). As early as around 11,000 years ago, sites from Turkey and Syria suggest that social organization began to change where concerted communal activity has been observed even before the transition to agriculture [80]. This may have begun with the herding of animals, which was also associated with greater collective behavior and belief systems as realized in monumental structures and "art." In this regard, the recently excavated Göbekli Tepe "temple" complex [81,82] created by hunter gatherers consists of large monumental carved stones, reliefs, and sculptures of various animals and humans. Again, this suggests hunter gatherers invested great energy and resources in ritual activities that took precedence over practical, utilitarian and economic interests. The pervasive and often maladaptive nature of this kind of thinking can therefore be found in the enormous resources directed towards building monuments to appease or glorify supernatural agents. This contradicts the notion that monumental art and architecture only arrived in tandem with settled agricultural communities. Further evidence has come to light that supports this proposition where the invention of ceramics 17,500-15,000 years ago occurred, not for utilitarian purposes for making vessels/pottery as was previously thought, but rather for creating sculptural objects (i.e., "art") in the service of ritual [83]. Thus, even before the arrival of the first settled agricultural communities, enormous time and effort was expended to create buildings and various artifacts for ritual purposes. Such maladaptive behavior continued into the era when the first settled agricultural communities arose during the Neolithic. The negative consequences of relying on associative thinking to solve immediate problems is aptly summarized by Ronald Wright [84] where he sets out the way various "civilizations", rather than confronting the real practical issues of survival, directed attention towards supernatural agents. The many ways in which ritual and associated activities were either self-destructive or served to direct the course of behavior in premodern societies has also been extensively catalogued by Edgerton [85] and Carneiro [51].

With the arrival of settled agricultural communities, territory came under the ownership of a particular group and therefore needed to be defended. The domestication of cereals and other crops, as well as animals, led to the need to protect such goods, which also spawned greater technological expertise that improved survival rates and led to a further increase in population levels. Of course, one of the consequences of having to defend land and associated products was the need for individuals with specialized skills capable of repulsing attackers from other communities intent on plunder, etc. This will have driven the need to be always one step ahead of one's opponents by inventing new ways of overcoming threat. On the plus side, however, a great advantage of higher population rates now living side by side in settled communities is that innovation increases as there are more opportunities 
for ideas and skills to be exchanged [45]. Thus, human "progress" seems to have involved a dynamic whereby cooperation and antagonism between groups constituted the main driving force, which, along with rising population levels, provided a gradient that allowed innovative technologies to proliferate. This was reinforced by a proclivity to adhere to group norms - a product of gene-culture coevolution - which was underpinned by punishment of those who transgressed group rules [44]. Although the Upper Paleolithic evinces an increase in technological prowess with signs of this also existing sporadically during the Middle Paleolithic [86], it was not until agricultural communities developed that the balance began to shift more toward practical concerns. For example, sophisticated carpentry is now thought to have appeared during the Neolithic, which led to increased deforestation and the clearing of land for agriculture [87]. This does not, however, imply that there was a sudden loss of interest in the power of the supernatural to influence events; rather the bias seemed to have shifted toward issues of practical import. Having said this, it needs to be again emphasized that many groups throughout the world continued and are continuing to base their world view on supernatural agents [51].

\subsection{Villages and Towns}

As societies became larger, even bigger defensive groups and alliances were required to match a similar tendency in other groups, which is why we see a progression from villages, towns, city states to nation states from antiquity to the modern age. Although, it should be added, this was by no means a linear process with some groups remaining fairly static, especially in isolated situations or where population levels/densities remained low. Moreover, the relationships between groups will have been flexible where exchange of goods and trade in periods of abundance tended to encourage cooperative tendencies. Technology and better communication systems have not only promoted more efficient sharing of information, but also the means to form larger integrated groups that adhere to generally accepted norms. This is formalized in institutions, whether ordained by religious dictate or what an elected consensus decides this should be. What is intriguing about these developments is that, although practical efficacy began to exert more of an influence, human cognition continued to rely on hunter gatherer thinking of the late Pleistocene. This derives from the enduring cognitive domains already referred to, especially those involving social functions. However, as emphasized, because a hypertrophied brain had given rise to surplus mental capacities, such domains were amenable to exploitation and colonization by accumulated cultural knowledge for purposes to which they were not originally designed [88]. The development of various technologies, whether related to farming, buildings, tools, etc., can be seen as the material embodiment of these redirected/reformatted information processing capabilities that depended on co-evolutionary epigenetic factors for their realization. A feedback mechanism will thus have occurred whereby, as more complex technologies were created through the ratchet effect, so greater amounts of information became fixed in both material form and in personal expertise capable of being transmitted to future generations, especially when population rates and densities increased significantly. The importance of the rise in population levels/densities cannot be underestimated because it is thought this provided the context that allowed information to be transmitted, extended, and passed on to subsequent generations $[45,75,76]$. 
Although the material items produced by humans encapsulated useful practical information that could be potentially transmitted, it was the invention of writing systems that was transformational. Despite speech serving as the predominant means of exchanging information long before writing, its impermanence rendered it relatively unreliable. Writing, however, provided an exceptionally dependable, efficient, and flexible means of transmitting information on many levels to future generations. Thus, it was the ability to share information in increasingly efficient ways in permanent form that, together with the rise in population levels/densities, led to a surrogate but shared interactive virtual "brain" [65]. As the brain had reached a natural limit in size and complexity, such an externalized virtual brain provided a means by which such restrictions could be circumvented [65]. Not only could knowledge now be shared intra-generationally but also inter-generationally with greater dependability that could be utilized to set up and manage institutions for achieving greater communal stability. This represents an extended level of information processing that allowed humans to domesticate themselves by changing the environmental niche by constructing of villages, towns, and cities within ever larger states and countries as population rates burgeoned. It is telling that, as population levels increased and the knowledge base expanded, thus giving rise to more and better technical innovations, states also expanded in size in order to meet the challenge from other population centers that were expanding at the same time. This gradient was nurtured by a process of fission and fusion [89] that had begun during the Neolithic when agriculture first took hold.

Although cumulative knowledge led to innovations that allowed larger populations, on average, to live in harmony, this did not mean cultural knowledge had neutralized the evolutionary instantiated domains already referred to. The fact that, despite the advantage of thousands of years of accumulated knowledge, humans continue to engage in hostile, often violent, actions involving nation states, suggests that these domains are as pertinent as ever. As we have seen, such enduring domains tend to determine behavior especially in times when threat prevails, yet, over the long term, cooperation appears to have counteracted the negative effects of enmity.

This brings us to a consideration of our attitude toward the natural world and how this plays out in the modern world. We have seen that there are evolutionary instantiated cognitive domains for dealing with the natural world, the perception of which led to different interpretations as to what such a world contained or implied. For the most part, this understanding was based on associative thinking where the idea there is a separation between the natural world and the self did not exist. Both the world and the subjective self were regarded as permeable and part of a flux whereby spirits and suchlike could inhabit things and influence the present and future in multiple ways [90,91]. Although such thinking was often counter-productive, it was nevertheless an attempt to "understand" and control nature that grew out of fear of its unpredictability and a respect for its immensity. This "understanding" was, however, still based on a need to affect the world in a way that could benefit humans, though this also led to a situation where humans were often drawn into the melee and suffered as a consequence. Following the Neolithic, this sensibility began gradually to wane, thanks to the influence of urban centers where knowledge was concentrated and shared between individuals who now engaged in specialized skills. This eventually led to practical, utilitarian modes of thinking coming to the fore. In effect, the supernatural, although continuing to be influential in some spheres, especially in relation to the moral and social as a means of controlling behavior, nevertheless became less dominant in other realms particularly where technical expertise was required. In the same way that the human anatomy, 
including the brain, has been the result of various structures arising one from another to create what has been termed a "kludge" [54], so human behavior/cognition and its material embodiment arose in a similar fashion involving a mishmash of various components, some driven by practical need whereas others continued to rely on more fanciful ideas.

\section{Consequences of Human Behavior}

To reiterate, one of the consequences of a brain conceived to cope with the complexities of social interaction was the ability not only to escape from the tyranny of the present but also the ability for conscious reflection. This kind of cognition inevitably gave rise to associative thinking in that the world as experienced phenomenologically needed to be explained. "Content biases," which are transmittable phenomena inherently memorable due to the intrinsic structure of the mind or the robust responses they evoke, e.g., the predilection for fairy tales or various myths [92], seem to be associated with this kind of thinking. Although the emphasis, from the Neolithic onwards, had progressively shifted towards understanding the world on a practical materially-based level, which led to obvious benefits for humankind, there has been a reluctance to apply this mode of thinking to socio-moral and religious concerns; mainly because this has been a highly sensitive area of investigation that strikes at the heart of a community's self-identity. It is only recently that the attraction of the supernatural (even Isaac Newton was fascinated by alchemy and the occult) has been superseded thanks to the insights of the Enlightenment and secular humanism. Yet, although Darwin demonstrated how humans are intimately related to the natural world in complex ways as is any other species, a human-centered outlook continues to prevail. By this I mean that the social factors fostered by evolution that led to the way the human brain evolved and how cognition and behavior became structured, and which determined how the world is viewed, continues in the modern world with respect to the way humans regard themselves. In other words, the social aspects of human interaction continue to hold sway but, thanks to improvements on the practical level, the social imperative has now been projected onto technology itself. In this scenario, whenever human concerns are threatened or at risk it is Hss who is given priority over issues concerning the natural world. In fact, it seems that the human prerogative takes precedence even when this involves trivial needs. This can be related to the evolutionary mediated preferences referred to earlier where things that were once difficult to acquire in our evolutionary past, sugar, fat, and salt etc., are now widely available almost without limit. Indeed, these kinds of biases are eagerly exploited by the media within a consumer-dominated society to the extent they have become commodity fetishes. Interestingly, Marx and Engels alluded to this type of fetishism as "the religion of sensuous appetites" [93]. Similarly, content biases have also been exploited by commerce, mainly through advertising and publicity, in that those aspects of the mind easily evoked due to our evolutionary past are exploited for commercial benefit. Thus, the social imperative is now expressed through objects that are deemed to have intrinsic value [94]. This tendency can be linked to obsessive behavior where individuals, and even whole communities, become addicted to objects as exemplified in various fads, fashions, and related activities. It is as if those parts of the brain that evolved to meet primary needs are now over stimulated when the need for such stimulation no longer exists and is often self-defeating. Obsessive behavior of this type may, in fact, have begun quite early, perhaps as far back as 500,000 years or more, when a concern for perfection in the form of 
symmetrical handaxes first occurred that went beyond the purely functional $[74,95,96]$. Many of these tools were also made in great numbers and discarded without apparently having been used [97]. This preference for the non-functional can also be observed in a concern for beads, crystals, as well as the making of cupules, repetitive lines and patterns [64]. As Bednarik [96] states, the artificial niche constructed by humans may be a consequence of an obsessive addiction, initially for the non-functional, then increasingly the functional.

The cognitive domains that were previously so important to the survival of humans during the Pleistocene, which were tied to the prevailing environmental conditions, therefore continue to operate in modern humans but are now liable to be either hyperstimulated, as described, or are usurped by other functions relating to the artificial niche in which humans now mainly reside. The latter point is particularly important insofar as advanced extra-somatic information capacities are concerned, e.g. writing and number systems that exploit long-standing cognitive domains for purposes for which they were not initially designed. It is notable that, as population numbers began to increase significantly during the Upper Paleolithic and Middle Stone Age, rates of innovation began to augment in both technical and art-like skills $[75,86]$. The invention of writing and numerical capacities will also have been a consequence of rising population trends where ideas were more likely to be shared in the context of more settled communities involving trade networks. Thus, culture allows a community to track and respond to any environmental events in a way that is more flexible than is the case for most other species because it is not tethered to genetic imperatives that respond more slowly over a number of generations. Yet, there lies the problem in the sense that the socio-cultural dimension has been so successful in allowing human population rates to expand that this now threatens not only the survival of humans but the biodiversity on which life mostly depends.

Perhaps Hss should more accurately categorized as Homo patternus obligatus as our obsession to seek out, deal with, and nurture various kinds of information on many different levels is obvious. In this sense, the brain is primarily concerned with detecting constancies of the world that promote survival. After all, a major part of the brain's function involves identifying and processing various kinds of pattern, a contingency that also applies to language and the decoding of social lifeways. This has developed to such a sophisticated level in Hss that the associated neural networks have become overly complex and convoluted, thereby giving rise to the aforementioned mental disorders, unknown in chimpanzees or bonobos, that typify humans as a result of the inherent instability involved [56,98]. Moreover, it is this seeking after pattern that appears to underwrite culture. As Holloway [99] states, culture can be defined as: "that complex whole...shared by man as a member of society...is also the imposition of arbitrary form upon the environment." Having found a pattern, humans tend to dwell on its merits. From this perspective, far from being a sophisticated ape, we are a very special and different kind of primate where a significant gulf separates us from even our closest living primate relatives [36]; that said, we are still a continuation of the line that evolved from earlier primates. Note, the reason Hss represents the only surviving Homo species may be due to the fact that we outcompeted other closely related hominins thanks to a flexibility that comes with a more complex brain capable of exploiting socio-cultural imperatives in the face of a rapidly changing environment. This fact, alone, may be why we appear to stand out from other primates in that we outcompeted other hominins to extinction. 
Similarly, it is believed that the demise of large animals during the end of the Pleistocene was, at least in part, due to the increased technological expertise attained through expanding human population levels - though climate change will also have been influential [100]. This trend can be observed in the Upper Paleolithic art where, in the earlier period, a greater number of large animals and predators were depicted compared to near the end of this epoch. These depictions, however, suggest there continued to be a reverence accorded to the animals portrayed. During the subsequent Mesolithic, the scenes in Levantine art suggest Hss completely dominated the remaining fauna as represented by groups of humans pursuing animals with various weapons. With the arrival of agriculture and settled communities the domination of animals continued, especially with the invention of new technologies for the clearance of forests, for growing crops, and the increasing domestication of key species. But these developments were never straightforward as many communities, even whole civilizations, were to rise then disappear, often due to over-exploitation of the prevailing natural resources that was invariably exacerbated by appealing to supernatural entities rather than taking the requisite practical action. The ability to manipulate symbolic information systems with ever greater efficiency also led to a quickening in the exchange of ideas that, in turn, led to increasingly efficacious means of exploiting natural resources. This was furthered by ever rapid modes of exchanging information beginning with the printed word and culminating in electronic systems that, with the rise of highly specialized individuals in particular fields of expertise, meant that ways to exploit the natural environment continued apace. Ultimately, these extra-somatic forms of exchanging information acted as an extended brain able to deal with information in ways that the brain itself is unable to achieve [63].

\subsection{Ecology and Environment}

As the natural environment throughout human evolutionary history was regarded as something to be feared or appeased (and therefore either respected or controlled) by whatever happened to be the presiding sensibility, this attitude continues today as can be seen by the rapid demise in biodiversity caused by human overconsumption. Although supernatural thinking saw the human and natural world as intimately related and interdependent, which included communing with and a respect for spirits on a number of levels, this was nevertheless predicated on the notion that through human intervention gods could be assuaged in order either to influence natural events or gain favor. Now that technologies exist that exert real control over nature, a rapid decline in species diversity has ensued. In the main, the natural world and corresponding biodiversity, rather than being regarded as something to be cherished continues to be seen as "the other" because of its apparent randomness that needs to be controlled to meet human needs.

This attitude continues in the recent notion techno solutions might be able to cure the problems caused by human activity, e.g. carbon capture, genetic tinkering, atmospheric control, etc., but as the natural world is a highly complex interdependent system we still do not fully understand such "solutions" may lead to even greater problems. For example, on every occasion where humans have intervened to restore the balance of nature, this has led to disaster. As the natural brain seems to have reached a self-imposed limit [97], it has even been suggested that we might be able to escape such a constraint by providing brain prosthesis capable of supplementing brain capacity [101,102]. As a result, it is surmised the usual Darwinian imperatives might be capable of being circumvented. Techno 
solutions to complex problems, however, when pitted against natural selection, tend always to come with a downside. For example, antibiotics may have helped guard against certain diseases in the short to medium term but, in the long run, bacteria build up a resistance making antibiotics ineffective. In addition, the notion that technology and the associated artificial niche have insulated humans from natural selection may be exaggerated as selection continues to operate on many levels in humans [103]. Nevertheless, because we have, in some contexts, been able to escape the raw forces of Darwinian evolution through gene-culture coevolution, this has led to the precarious situation we now find ourselves in vis-a-vis climate change and the astounding loss in species biodiversity. If we are indeed now in the Anthropocene, characterized by such changes where one species, namely Hss, is responsible, it needs to be borne in mind that, in the same way as in previous geological periods, climate can respond rapidly to alterations to the prevailing equilibrium. If the examples of the collapse of previous civilizations are anything to go by [84], we may be already in the midst of yet another such demise but on a global rather than a localized scale. Climate change could, accordingly, be the means by which Darwinian imperatives have the last word in bringing humans back into its fold.

\section{Discussion}

The foregoing suggests that humans are a special primate with qualities and a behavioral profile very different to that of our closest existing relatives. The evolutionary trajectory through which this was achieved involved a unique series of events over six million years where the brain expanded and developed in tandem not only in response to environmental conditions but also social factors, cultural input, and emerging technologies [89]. This involved a growing flexibility which, although at first extremely modest, became significant when the brain reached its maximum size and complexity that was augmented by accumulated culture and rising population levels. Although supernatural thinking constrained practical solutions to environmental problems, as a result of a greater sharing of ideas, this eventually led to a mental set that became disposed towards the practical that could potentially deal with such problems. However, the products deriving from the technologies concerned became increasingly faddish by appealing to content biases that now no longer satisfy essential needs but are repeatedly indulged to the detriment of the natural environment itself. Although a practical utilitarian mode of relating to the world has come to the fore during the modern age, much human activity continues to be centered around social concerns where enduring cognitive domains from a hunter gatherer past influence and direct behavior on two levels. First, through a consumer-driven society that is parasitic on such domains, which has led to an over-exploitation of scarce resources to the extent that this has been detrimental to both ourselves and the biosphere. Second, by continuing to engage in maladaptive thinking whereby irrational thought processes largely determine behavior. In addition, although humans seem, on one level, to have overcome the struggle with the natural world, this has now been replaced by a struggle between existing cultural groups that takes place within the humanly generated artificial niche. The "progress" that modern humans enjoy, however, is one that stemmed from an aggression/cooperation dynamic where cooperation seems to have been the dominant force but which, nevertheless, has deleterious consequences for the natural world. Having said this, humans can be regarded as a privileged species in that they are able to reflect not only on their own destiny but how this impacts on other species. Despite this, human endeavor continues to be constrained by 
enduring cognitive dictates unique to us as a species and it is only through enormous intellectual effort that such constraints can be overcome. Unfortunately, most of the world's population continues to base its judgments and belief systems on the former rather than the latter; a fact that applies to Western democratic systems where a consumer mentality continues to flagrantly exploit the inherent vulnerabilities and tendencies of the human brain with all the disastrous consequences this has for the environment.

\section{Conclusions}

One of the main themes emerging from the present analysis is that humans have become an invasive species to such an extent we now pose a danger not only to ourselves but many of the other species on the planet. This has arisen from the fact that human brain capacity has provided the competence to achieve many things on many levels that allows the manipulation of arbitrary informational systems that has led to a "patterned insanity" [7]. Yet, some human achievements have been truly impressive but the price to be paid has been modes of thinking and acting that have not been in the best interests of humans or other species. One of the main reasons for this state of affairs concerns the many maladaptive practices that necessarily accompany a large complex brain that allows the irrational to be treated and acted on as if real. A great paradox of human existence also consists in our ability to reflect on events by escaping from immediate imperatives. This has allowed an understanding of the fundamentals of nature yet, at the same time, we remain tied to such contingencies in being unable to dispassionately consider the dichotomous aspects of human behavior that are a fundamental attribute of our human heritage. In the last resort, human existence as presently configured, continues to depend on an antagonistic-cooperative interactive dynamic to the extent that the various achievements remain a product of this dynamic. Although there seems to have been a bias towards cooperative affiliation, this continues to center on humans as a species. Whether such a cooperative sensibility can eventually extend to other species with whom we share this planet before many of them become extinct remains to be seen but the omens are not good.

\section{References}

1. Michael Haslam. "Towards a prehistory of primates.” Antiquity 86 (2012): 299-315.

2. Jan Zalasiewicz, Mark Williams, Will Steffen, and Paul Crutzen. "The New World of the Anthropocene." Environment Science and Technology 7 (2010): 2228-31.

3. Gen Suwa, Berhane Asfaw, Reiko T. Kono, Daisuke Kubo, C. Owen Lovejoy, and Tim D. White. "The Ardipithecus ramidus Skull and its Implications for Hominid Origins." Science 326 (2009): 68e1-68e7.

4. Sileshi Semaw, Michael. J. Rogers, Jay Quade, Paul R. Renne, Robert F. Butler, Manuel Dominguez-Rodrigo, Dietrich Stout, William S. Hart, Travis Pickering, and Scott. W. Simpsoni. "2.6-Million-year-old stone tools and associated bones from OGS-6 and OGS-7, Gona, Afar, Ethiopia." Journal of Human Evolution 45 (2003): 169-77.

5. Nicholas Toth, and Kathy Schick. "The Oldowan: The Tool Making of Early Hominins and Chimpanzees Compared." Annual Review of Anthropology 38 (2009): 289-305. 
6. Ita Roffman, Sue Savage-Rumbaugh, Elizabeth Rubert-Pugh, Avraham Ronen, and Eviatar. Nevo. "Stone tool production and utilization by bonobo-chimpanzees (Pan paniscus)." Proceedings of the National Academy of Sciences USA 109 (2012): 14500-03. doi:10.1073/pnas.1212855109.

7. Ralph Holloway. "The Human Brain Evolving: A Personal Retrospective." Annual Review of Anthropology 37 (2008): 1-19.

8. Meave G. Leakey, Fred Spoor, M. Christopher Dean, Craig S. Feibel, Susan C. Antón, Christopher. Kiarie, and Louise N. Leakey. "New fossils from Koobi Fora in northern Kenya confirm taxonomic diversity in early Homo." Nature 488 (2012): 201-04. doi:10.1038/nature11322.

9. Terence Deacon. The Symbolic Species: the Co-evolution of Language and the Human Brain. London: Allen Lane, 1997.

10. Robin Dunbar. "The Social Brain: Mind, Language, and Society in Evolutionary Perspective." Annual Review of Anthropology 32 (2003): 163-81.

11. Daniel Dennett. Consciousness Explained. London: Penguin, 1993.

12. Derek Hodgson. "Ways of Seeing - The Innocent Eye, Individual View and Visual Realism in Art." Journal of Consciousness Studies 12 (2004): 3-16.

13. Gerald M. Edelman. "Naturalizing consciousness: a theoretical framework." Proceedings of the National Academy of Sciences U.S.A. 100 (2003): 5520-24.

14. Matt J. Rossano. Expertise and the evolution of consciousness. Cognition 3 (2003): 207-36.

15. Jerome H. Barkow, Leda Cosmides, and John Tooby. The adapted mind: Evolutionary psychology and the generation of culture. Oxford: Oxford University Press, 1992.

16. Jaime C. Confer, Judith A. Easton, Diana S. Fleischman, Cari. D. Goetz, David. M. G. Lewis, Carin Perilloux, and David M. Buss. "Evolutionary psychology: Controversies, questions, prospects, and limitations." American Psychologist 2 (2010): 110-26.

17. Arne Öhman, and Susan Mineka. "Fears, phobias, and preparedness: Toward an evolved module of fear and fear learning." Psychological Review 3 (2001): 483-522.

18. Ara Norenzayan, Mark Schaller, and Stephen J. Heine, "Introduction." In Evolution, Culture and the Human Mind, edited by Ara Norenzayan, Mark Schaller, Stephen J. Heine, and Toshio Yamagishi. New York: Psychology Press, 2009, 1-5.

19. Cecilia Heyes. "Grist and mills: on the cultural origins of cultural learning." Philosophical Transactions of the Royal Society B 367 (2012): 2181-2191. doi:10.1098/rstb.2012.0120.

20. Peter J. Richerson, and Robert Boyd. Not by genes alone: How culture transformed human evolution. Chicago: University of Chicago Press, 2005.

21. Paul E. Griffiths. "Evo-Devo Meets the Mind: Toward a Developmental Evolutionary Psychology." In Integrating Evolution and Development: From Theory to Practice, edited by Roger Sansom, and Robert N. Brandon. Cambridge: Bradford Books, 2007, 195-225.

22. Fiona Coward, and Matt Grove. "Rethinking Phylogeny and Ontogeny in Hominin Brain Evolution." Human Evolution 1 (2012): 65-91.

23. Scott Atran, and Joseph. Henrich. "The Evolution of Religion: How Cognitive By-Products, Adaptive Learning Heuristics, Ritual Displays, and Group Competition Generate Deep Commitments to Prosocial Religions.” Biological Theory 5 (2010): 18-30. 
24. Robert Boyd, and Peter J. Richerson. "Group Selection among Alternative Evolutionarily Stable Strategies.” Journal of Theoretical Biology 145 (1990): 331-42.

25. Charles S. Spencer, and Elsa M. Redmond. "Multilevel Selection and Political Evolution in the Valley of Oaxaca." Journal of Anthropological Archaeology 20 (2001): 195-229.

26. Robert Boyd, and Peter J. Richerson. "Why Culture is Common, but Cultural Evolution is Rare." In The Origin and Evolution of Cultures, edited by R. Boyd, and P. J. Richerson. New York: Oxford University Press, 2005, 52-65.

27. Robin Dunbar. "The social brain meets neuroimaging." Trends in Cognitive Sciences 2 (2012): 101-102.

28. Joseph H. Manson, and Richard W. Wrangham. "Intergroup aggression in chimpanzees and humans." Current Anthropology 32 (1991): 369-90.

29. James K. Rilling, Jan Scholz, Todd. M. Preuss, Matthew F. Glasser, Bhargav K. Errangi, and Timothy. E. Behrens. "Differences between chimpanzees and bonobos in neural systems supporting social cognition." Social Cognitive and Affective Neuroscience. (2011) doi:10.1093/scan/nsr017.

30. Brian Hare, Alicia P. Melis, Vanessa Woods, Sara Hastings, and Richard Wrangham. "Tolerance allows Bonobos to Outperform Chimpanzees on a Cooperative Task." Current Biology 17 (2007): 619-623. doi: 10.1016/j.cub.2007.02.040.

31. Tomoko Sakai, Akichika Mikami, Masaki Tomonaga, Mie Matsui, Juri Suzuki, Yusuru Hamada, Masayuki Tanaka, Takaku Miyabe-Nishiwaki, Haruyuki Makishima, and Masato Nakatsukasa, et al. "Differential Prefrontal White Matter Development in Chimpanzees and Humans." Current Biology 16 (2011): 1397-1402.

32. Polly Wiessner. "Risk, reciprocity and social influences on !Kung San economics." In Politics and History in Band Societies, edited by Eleanor. Leacock, and Richard B. Lee. New York: Cambridge University Press, 1982, 61-84.

33. Polly Wiessner. "Style and social information in Kalahari San Projectile Points." American Antiquity 2 (1983): 253-75.

34. Robin Dunbar. "The Social Brain Hypothesis.” Evolutionary Anthropology 6 (1998): 178-190.

35. Robin Dunbar. The Human Story. London: Faber and Faber, 2004.

36. Robin Dunbar. "Mind the gap: or why humans aren't just great apes." Proceedings of the British Academy 154 (2009): 403-23.

37. Atsushi Iriki. "The neural origins and implications of imitation, mirror neurons and tool use." Current Opinions in Neurobiology 16 (2006): 660-67.

38. Leslie C. Aiello, and Peter Wheeler. "The Expensive-Tissue Hypothesis: The Brain and the Digestive System in Human and Primate Evolution." Current Anthropology 36 (1995): 199-221.

39. Fiona Coward, and Clive Gamble. "Big brains, small worlds: material culture and the evolution of the mind." Philosophical Transactions of the Royal. Society B 363 (2008): 1969-79.

40. Clive Gamble, John Gowlett, and Robin Dunbar. "The Social Brain and the Shape of the Palaeolithic." Cambridge Archaeological Journal 1 (2011): 115-35.

41. Andrew Whiten. "The scope of culture in chimpanzees, humans and ancestral apes." Philosophical Transactions of the Royal Society B 366 (2011): 997-1007. 
42. Randy L. Buckner, and Daniel C. Carroll. "Self-projection and the brain." Trends in Cognitive Sciences 2 (2007): 49-57.

43. Francesco d'Errico. "The Invisible Frontier. A Multiple Species Model for the Origin of Behavioral Modernity.” Evolutionary Anthropology 12 (2003): 188-202.

44. Robert Boyd, Peter J. Richerson, and Joseph Henrich. "Cultural Evolution of Human Cooperation." In The Origin and Evolution of Cultures, edited by R. Boyd, and P. J. Richerson. New York: Oxford University Press, 2005, 251-81.

45. Derek Hodgson. "Determining the behavioural profile of early modern humans: assimilating population dynamics and cognitive abilities." Before Farming, 2010/2, article 1. http://www.waspress.co.uk/journals/beforefarming/journal_20102/index.php.

46. Emiliano Bruner, Giogio Manzi, and Juan Luis Arsuaga. "Encephalization and allometric trajectories in the genus Homo: evidence from the Neanderthal and modern lineages." Proceedings of the National Academy of Sciences USA 6 (2003): 15335-40.

47. Emiliano Bruner. "Morphological Differences in the Parietal Lobes within the Human Genus: A Neurofunctional Perspective." Current Anthropology 51(2010): Supp. 1, S77-S88.

48. Antoine Balzeau, Ralph L. Holloway, and Dominique Grimaud-Hervé. "Variations and asymmetries in regional brain surface in the genus Homo." Journal of Human Evolution 62 (2012): 696-706.

49. Robert Boyd. "Cultural adaptation and maladaptation: Of kayaks and commissars." In The Evolution of Mind: Fundamental Questions and Controversies, edited by Steven W. Gangestad, and Jeffry A. Simpson. New York: Guilford Press, 2007, 327-331.

50. Scott Schieman. "Socioeconomic Status and Beliefs about God's Influence in Everyday Life." Sociology of Religion 1 (2010): 25-51.

51. Robert L. Carneiro. The Evolution of the Human Mind: From Supernaturalism to Naturalism-An Anthropological Perspective. New York: Eliot Werner, 2010.

52. Krist Vaesen. "The cognitive bases of human tool use." Behavioral and Brain Sciences. 4 (2012): 203-18. doi: 10.1017/S0140525X11001452.

53. Kevin N. Laland, John Odling-Smee, and Sean Myles. "How culture shaped the human genome: bringing genetics and the human sciences together." Nature Reviews Genetics 11 (2010): 137-48.

54. John M. Allman. Evolving Brains. New York: Scientific American Library, 1999.

55. Asif A. Ghazanfar. "Language evolution: neural differences that make a difference." Nature Neuroscience 4 (2008): 382-84.

56. Genevieve Konopka, Tara Friedrich, Jeremy Davis-Turak, Kellen Winden, Michael. C. Oldham, Fuying Gao, Leslie Chen, Guang-Zhong Wang, Rui Luo, and Todd M. Preuss, et al. "HumanSpecific Transcriptional Networks in the Brain.” Neuron 75 (2012): 601-17.

57. Martin Brune "Neoteny, psychiatric disorders and the social brain: Hypotheses on heterochrony and the modularity of the mind." Anthropology and Medicine 3 (2000): 301-18.

58. Robert G. Bednarik, and Patricia A. Helvenston, "The nexus between neurodegeneration and advanced cognitive abilities." Anthropos 2 (2011): 511-28.

59. Marco Catani, and Dominic H. ffytche. "The rises and falls of disconnection syndromes." Brain 128 (2005): 2224-39. doi:10.1093/brain/awh622. 
60. B. T. Thomas Yeo, Fenna. M. Krienen, Jorge Sepulcre, Mert R. Sabuncu, Danial Lashkari, Marisa Hollinshead, Joshua L. Roffman, Jordon W. Smoller, Lilla Zöllei, and Jonathan R. Polimeni, et al. "The organization of the human cerebral cortex estimated by intrinsic functional connectivity." Journal of Neurophysiology 106 (2011): 1125-65.

61. Timothy J. Crow. "A Darwinian approach to the origins of psychosis." The British Journal of Psychiatry 167 (1995): 12-25.

62. Larry S. Barham. "Systematic pigment use in the Middle Pleistocene of south-central Africa." Current Anthropology 43 (2002): 181-190.

63. Merlin Donald. Origins of the modern mind: three stages in the evolution of culture and cognition. Cambridge: Harvard University Press, 1991.

64. Robert G. Bednarik. "The earliest evidence of palaeoart." Rock Art Research 2 (2003): 89-135.

65. Derek Hodgson. “Art, perception and information processing: an evolutionary perspective.” Rock Art Research 17 (2000): 3-34.

66. Frederick L. Coolidge, and Thomas Wynn. The Rise of Homo Sapiens: The Evolution of Modern Thinking. Chichester: Wiley-Blackwell, 2009.

67. Dietrich Mania, and Ursula Mania. "The natural and socio-cultural environment of Homo erectus at Bilzingsleben, Germany." In The Hominid Individual in Context, edited by Clive Gamble and Martin Porr. London: Routledge, 2005, 98-114.

68. Paul Pettitt. "Religion and Ritual in the Lower and Middle Palaeolithic." In The Oxford Handbook of the Archaeology of Ritual and Religion, edited by T. Insoll, Oxford: Oxford University Press, 2011, 329-43.

69. Robert Boyd, and Peter J. Richerson. "Why does culture increase adaptability?" Ethology and Sociobiology 2 (1995): 125-43.

70. Joseph Henrich, and Robert Boyd. "The evolution of conformist transmission and the emergence of between-group differences." Evolution and Human Behavior 19 (1998): 215-42.

71. Azim F. Shariff, Ara Norenzayan, and Joseph Henrich. "The Birth of High Gods: How the cultural evolution of supernatural policing agents influenced the emergence of complex, cooperative human societies, paving the way for civilization." In Evolution, Culture and the Human Mind, edited by Mark Schaller, Ara Norenzayan, Steven J. Heine, Toshio Yamagishi, and Tatsuya Kameda. New York: Psychology Press, 2009, 117-36.

72. Jan Verpooten. "Brian Boyd's Evolutionary Account of Art: Fiction or Future?" Biological Theory 6 (2011): 176-83. doi: 10.1007/s13752-012-0023-9.

73. Peter Richerson, and Joseph Henrich. "Tribal social instincts and the cultural evolution of institutions to solve collective action problems." Cliodynamics 3 (2012): 38-80.

74. Derek Hodgson. "Hominin Tool Production, Neural Integration and the Social Brain." Human Origins 1 (2012): 41-64.

75. Adam Powell, Stephen Shennan, and Mark G. Thomas. "Late Pleistocene Demography and the Appearance of Modern Human Behavior.” Science 324 (2009): 1298-1301.

76. Adam Powell, Stephen Shennan, and Mark G. Thomas. "Demography and Variation in the Accumulation of Culturally Inherited Skills." In Innovation in Cultural Systems: Contributions from Evolutionary Anthropology, edited by M. J. O`Brian, and S. J. Shennan, Cambridge: MIT Press, 2010, 137-60. 
77. Stephen Shennan. "Demography and cultural innovation: a model and its implications for the emergence of modern human culture." Cambridge Archaeological Journal 11 (2001): 5-16.

78. Frans L. Roes, and Michel Raymond."Belief in moralizing gods." Evolution and Human Behavior 24 (2003): 126-35.

79. Jacques Cauvin. The birth of the gods and the origins of agriculture (Trevor Watkins, Trans.). Cambridge: Cambridge University Press, 1999.

80. Steven J. Mithen, Bill Finlayson, Sam Smith, Emma Jenkins, Mohammed Najjar, and Darko Maričević. "An 11, 600 year-old communal structure from the Neolithic of southern Jordan." Antiquity 85 (2011): 350-64.

81. Klaus Schmidt. "Ritual centers' and the Neolithisation of Upper Mesopotamia.” Neo-Lithics 5 (2005): 13-21.

82. Oliver Dietrich, Manfred Heun, Jens Notroff, Klaus Schmidt, and Martin Zarnkow. "The role of cult and feasting in the emergence of Neolithic communities. New evidence from Gőbekli Tepe, south-eastern Turkey." Antiquity 86 (2012): 674-95.

83. Rebecca Farbstein, Dinko Radic, Dejana Brajkovic, and Preston T. Miracle. "First Epigravettian Ceramic Figurines from Europe (Vela Spila, Croatia)." PLoS ONE 7 (2012): e41437. doi:10.1371/journal.pone.0041437.

84. Ronald Wright. A Short History of Progress. Edinburgh: Canongate, 2004.

85. Robert B. Edgerton. Sick Societies: Challenging the Myth of Primitive Harmony. New York: Free Press, 1992.

86. Marlize Lombard. "Thinking through the Middle Stone Age of sub-Saharan Africa." Quaternary International 270 (2012): 140-55.

87. Richard W. Yerkes, Hamudi Khalaily, and Ran. Barkai. "Form and Function of Early Neolithic Bifacial Stone Tools Reflects Changes in Land Use Practices during the Neolithization Process in the Levant." PLoS ONE 8 (2012): e42442. doi:10.1371/journal.pone.0042442.

88. Stanislas Dehaene, and Laurent Cohen. "Cultural Recycling of Cortical Maps." Neuron 56 (2007): 384-98.

89. Robert Foley, and Clive Gamble. "The ecology of social transitions in human evolution." Philosophical Transactions of the Royal Society B 364 (2009): 3267-79.

90. Tim Ingold. "Rethinking the animate, re-animating thought." Ethnos 71 (2006): 9-20.

91. Carlos Fausto. "Feasting on people: Eating animals and humans in Amazonia." Current Anthropology 48 (2007): 497-530.

92. Stephen Shennan. "Evolution in Archaeology." Annual Review of Anthropology 37 (2008): 75-91.

93. Karl Marx, and Friedrich Engels. On Religion. Atlanta: Scholars, 1982.

94. Roland Boer. "That Hideous Pagan Idol: Marx, Fetishism and Graven Images." Critique: Journal of Socialist Theory 1 (2010): 93-116.

95. Derek Hodgson. "Symmetry and humans: Reply to Mithen's 'Sexy Handaxe Theory'." Antiquity 83 (2009): 195-98.

96. Robert G. Bednarik. “The origins of human modernity.” Humanities 1 (2012): 1-53.

97. Thomas Wynn. "Handaxe enigmas.” World Archaeology 27 (1995): 10-23.

98. Philipp Khaitovich, Helen E. Lockstone, Matthew T. Wayland, Tsz M. Tsang, Samantha D. Jayatilaka, Arfu J. Guo, Jie Zhou, Mehmet Somel, Laura W. Harris, and Elaine Holmes, et al. 
"Metabolic changes in schizophrenia and human brain evolution." Genome Biology 9 (2008): R124. doi:10.1186/gb-2008-9-8-r124.

99. Ralph Holloway. "Language and tool making are similar cognitive processes." Behavioral and Brain Sciences 4 (2012): 226. doi:10.1017/S0140525X11002019.

100. Eline D. Lorenzen, David Nogués-Bravo, Ludovic Orlando, Jaco Weinstock, Jonas Binladen, Katharine A. Marske, Andrew Ugan, Michael K. Borregaard, Thomas P. Gilbert, and Rasmus Nielsen, et al. "Species-specific responses of Late Quaternary megafauna to climate and humans." Nature 479 (2011): 359-64. doi: 10.1038/nature10574.

101. Michel A Hofman. "Brain evolution in hominids: are we at the end of the road?" In Evolutionary Anatomy of the Primate Cerebral Cortex, edited by Dean Falk and Kathleen Gibson, Cambridge: Cambridge University Press, 2001, 113-27.

102. Timothy Taylor. The Artificial Ape: How Technology Changed the Course of Human Evolution. New York: Palgrave Macmillan, 2010.

103. Russell Powell. "The Future of Human Evolution." British Journal for the Philosophy of Science 1 (2012): 145-75.

(C) 2012 by the author; licensee MDPI, Basel, Switzerland. This article is an open access article distributed under the terms and conditions of the Creative Commons Attribution license (http://creativecommons.org/licenses/by/3.0/). 